and helped with its technical aspects, and also the patients who took part in this study.

Funding: This study was funded by the Cancer Research Campaign and the Bob Champion Cancer Trust. Conflict of interest: None.

1 Davis H, Fallowfield L. Counselling and communication in health care. 4th ed. Chichester: Wiley, 1991.

2 Spiegel D, Bloom JR, Yalom I. Group support for patients with metastatic cancer. Arch Gen Psychiatry 1981;38:527-33.

3 Fawzy I, Cousins N, Fawzy NW, Kemeny ME, Elashoff R, Morton D. A structured psychiatric intervention for cancer patients. Arch Gen Psychiatry 1990;47:720-5.

4 Greer S, Moorey S, Baruch JDR, Watson M, Robertson BM, Mason A, et al. Adjuvant psychological therapy for patients with cancer: a prospective randomised trial. BMJ 1992;304:675-80.

5 Moorey S, Greer S. Adjuvant psychological therapy for patients with cancer: outcome at one year. Psycho-Oncology 1994;3:39-46.

6 Bloom JR, Ross RD, Burnell G. The effect of social support on patient adjustment after breast surgery. Patient Counselling Health Educ 1978; Autumn:50-9.

7 Golonka LM. The use of group counselling with breast cancer patients receiving chemotherapy. Dissertation Abstracts International 1977;37: 6362-3.

8 Moynihan C. Psychosocial assessments and counselling. In: Horwich A, ed. Testicular cancer: investigation and management. London: Chapman and Hall, 1996.

9 Moynihan C. Testicular cancer: the psychosocial problems of patients and their relatives. Cancer Surv 1987;6:477-510.

10 Rieker PP, Fitzgerald EM, Kalish LA, Richie JP, Lederman GS, Edbril SD, et al. Psychosocial factors, curative therapies and behavioural outcomes: a comparison of testis cancer survivors and a control group of healthy men. Cancer 1989;64:2399-406.

11 House A, Knapp P. Trials that use Zelen's procedure should be acceptable. BMJ 1997:315:251.
12 Vingerhoets A, van Heck G. Gender, coping and psychosomatic symptoms. Psychol Med 1990;20:125-35.

13 Moorey S, Greer S. Psychological therapy for patients with cancer: a new approach. Oxford: Heinemann Medical, 1989.

14 Zigmond AS, Snaith RP. The hospital anxiety and depression scale. Acta Psychiatr Scand 1983;67:361-70.

15 Greer S, Watson M. Mental adjustment to cancer: its measurement and prognostic importance. Cancer Surv 1987;6:439-53.

16 Derogatis LR. Psychosocial adjustment to illness scale (PAIS-SR). Baltimore, MD: Clinical Psychometric Research, 1983

17 De Haes JC, Knippenberg FC, Nejit JP. Measuring psychological and physical distress in cancer patients: structure and application of the Rotterdam symptom checklist. Br J Cancer 1990;62:1034-8.

18 Brannon R, Juni S. A scale for measuring attitudes about masculinity. Psychol Doc 1984;14:2612.

19 Wing JK, Cooper JE, Sartorius N. The measurement and classification of psychiatric symptoms. Cambridge: Cambridge University Press, 1980.

20 Bauman LJ, Gervey R, Siegel K. Factors associated with cancer patients' participation in support groups. J Psychosoc Oncol 1992;10(3):1-20.

21 Fahy T, Wessely S. Should purchasers pay for psychotherapy? BMJ 1993;307:576-7.

(Accepted 22 October 1997)

\section{Correction}

Randomised controlled trial to evaluate early discharge scheme for patients with stroke

An authors' error occurred in this paper by Anthony G Rudd et al (25 October, pp 1039-44). In table 3 the $P$ value for the hospital anxiety and depression scale should have read 0.06 rather than 0.02 .

\title{
Evaluation of reagent strips in detecting asymptomatic bacteriuria in early pregnancy: prospective case series
}

\author{
Douglas G Tincello, David H Richmond
}

\begin{abstract}
Objective: To evaluate the performance of reagent test strips in screening pregnant women for asymptomatic bacteriuria at their first visit to an antenatal clinic.

Design: Prospective case series.

Setting: Antenatal clinic of a large inner city maternity hospital.

Subjects: All women attending for their first antenatal clinic. Patients taking antibiotics for any reason and those with urinary tract symptoms were excluded. Intervention: A midstream urine specimen was divided; half was sent for microscopy and formal bacteriological culture and the other half was tested with a commercial reagent strip test for the presence of blood, protein, nitrite, and leucocyte esterase.

Main outcome measures: Sensitivity, specificity, and positive and negative predictive values of the reagent strips in diagnosing asymptomatic bacteriuria (defined as $10^{5}$ colony forming units $/ \mathrm{ml}$ urine).

Results: Sensitivity was low, with a maximum of 33\% when all four tests were used in combination. Specificity was high, with typical values of $99 \%$ or more. Positive predictive value reached a maximum of $69 \%$ and negative predictive value was typically $95 \%$ or more.
\end{abstract}

Conclusion: Urine reagent strips are not sufficiently sensitive to be of use in the screening for asymptomatic bacteriuria and therefore many patients would be missed. In view of the potentially serious sequelae of this condition in pregnant women we recommend that formal bacteriological investigation remain the investigation of choice in this group of patients.

\section{Introduction}

Reagent strip testing of urine specimens for infection has become widespread in many areas of clinical practice. Such strips were sensitive and specific when used to exclude urinary tract infection in patients attending a urodynamic clinic ${ }^{1}$ and in pregnant women with symptoms of urinary tract infection. ${ }^{2}$ These reagent strips can undoubtedly realise substantial cost savings by reducing the need to send urine specimens for formal microscopy and culture, ${ }^{2-4}$ but none of the published studies has examined the performance of reagent test strips as a screening test for asymptomatic bacteriuria exclusively in women attending their first antenatal clinic.

Asymptomatic bacteriuria is defined as a pure culture of at least $10^{5}$ organisms $/ \mathrm{ml}$ of urine. ${ }^{5}$ Detection of all women with asymptomatic bacteriuria is important as $25 \%$ to $30 \%$ will develop symptomatic urinary tract infection while pregnant. ${ }^{6}$ The sequelae of urinary tract infection in pregnancy include pyelonephritis, premature labour, and preterm rupture of the membranes. $^{578}$ In view of the potential importance of
Department of Urogynaecology, Liverpool Women's Hospital, Liverpool L8 7SS

Douglas G Tincello, research registrar David H Richmond, consultant gynaecologist

Correspondence to: Dr Tincello

BMJ 1998;316:435-7 
Reagent strip performance in screening for asymptomatic bacteriuria in women at 12 to 14 weeks' gestation compared with two studies

\begin{tabular}{|c|c|c|c|c|c|c|c|}
\hline & $\begin{array}{l}\text { Sample } \\
\text { size }\end{array}$ & $\begin{array}{c}\text { No with } \\
\text { bacteriuria }\end{array}$ & $\begin{array}{l}\text { No with } \\
\text { positive test } \\
\text { results }\end{array}$ & $\begin{array}{l}\text { Sensitivity (\%) } \\
\text { (95\% CI) }\end{array}$ & $\begin{array}{l}\text { Specificity (\%) } \\
(95 \% \text { CI) }\end{array}$ & $\begin{array}{l}\text { Positive predictive } \\
\text { value (\%) }(95 \% \mathrm{CI})\end{array}$ & $\begin{array}{l}\text { Negative predictive } \\
\text { value }(\%)(95 \% \mathrm{CI})\end{array}$ \\
\hline Nitrite test & 893 & 48 & 9 & 18.8 (5.0 to 32.6$)$ & 99.5 (99.1 to 99.9$)$ & 69.2 (44.2 to 94.2$)$ & 95.6 (94.3 to 96.9$)$ \\
\hline Etherington and James ${ }^{2}$ & 898 & 27 & 18 & 67.5 & 99.7 & 90.0 & 98.5 \\
\hline Robertson and Duff ${ }^{4}$ & 750 & 62 & 27 & 43.4 & 98.9 & 79.4 & 95.1 \\
\hline All four tests in combination* & 893 & 48 & 16 & $33.3(26.5$ to 40.1$)$ & 91.1 (89.1 to 93.1$)$ & 17.6 (9.8 to 25.4$)$ & 96.0 (94.6 to 97.4$)$ \\
\hline Etherington and James ${ }^{2}$ & 898 & 27 & 2 & 8.18 & 79.0 & 17.6 & 96.0 \\
\hline
\end{tabular}

*Blood, protein, nitrite, and leucocyte esterase.

asymptomatic bacteriuria it is current practice in our hospital (in line with many other hospitals in the country) to send a urine sample for laboratory analysis from all patients who book for antenatal care. This study was performed to evaluate the performance of a commercially available reagent test strip in detecting asymptomatic bacteriuria in pregnant women booking for antenatal care.

\section{Subjects and methods}

From June 1996 to September 1996 all patients first attending the antenatal booking clinics at this hospital between 12 and 14 weeks' gestation were included in the study. Patients who had symptoms of lower urinary tract infection (except increased frequency alone) or who were taking antibiotics for any reason were excluded. A midstream specimen of urine was obtained in the clinic and divided; one half was sent for microscopy and formal culture according to standard practice, and the other half was tested with a reagent test strip (Ames 8SG Multistix; Bayer Diagnostics, Basingstoke). These reagent strips have panels that detect protein, blood, nitrite, and leucocyte esterase in urine. The presence of each of these substances is indicated by a specific colour change in the relevant panel. All samples were tested by midwifery staff in the clinic according to the manufacturer's instructions. The test results were compared visually with the colour charts on the reagent strip bottle and were read at the time specified in the instructions-after between 30 and 60 seconds. A positive test was defined as a strip showing any of the following: more than a trace of protein, more than a trace of blood, any positive result for nitrite, or any positive result for leucocyte esterase. A urine culture was defined as positive if the culture showed significant bacteriuria $\left(10^{5}\right.$ colony forming units $/ \mathrm{ml}$ of urine, regardless of the presence or absence of leucocytes). A culture was defined as contaminated if there was a mixed culture of any density or if there was a pure culture of less than $10^{5}$ colony forming units $/ \mathrm{ml}$. Cultures in which there was no growth of bacteria were classed as negative. Using these criteria the sensitivity, specificity, and positive and negative predictive values were calculated for each test alone and for all four tests in all combinations.

\section{Results}

During the study period 960 women booking in for antenatal care were eligible. Thirty five women were excluded: five patients were taking antibiotics, 21 patients had symptoms of urinary tract infection, and nine samples were lost during processing. Thirty two of the remaining 925 samples were contaminated and therefore excluded from further analysis. Of the 893 samples included in the study, 48 showed significant bacteriuria, of which 17 had associated leucocytosis. Twenty seven of the 48 samples produced a pure growth of coliforms, 5 a pure growth of group B streptococci, 4 a pure growth of Staphylococcus aureus, and the remainder pure growths of other streptococci (3 samples), enterococcus (4), Staphylococcus albus (4), and proteus (1).

The performance of each reagent alone and in combination with the others was examined. We considered sensitivity to be the most important attribute of the test, with positive predictive value the second most important attribute. Nitrite was the single reagent that showed good sensitivity and positive predictive value, and four tests in combination showed the best results. For clarity only the datasets for nitrite and all four tests in combination are shown in the table and compared with other published series.

\section{Discussion}

Reagent strip testing of antenatal urine specimens is effective and accurate when used to screen for bacteriuria in an effort to reduce the cost of urine analysis and culture. In a study of 898 samples the routine use of reagent strips would result in a saving of over $£ 4000$ a year in a busy inner city hospital. ${ }^{2}$ Such savings, however, meant that $25 \%$ of infected urine specimens were missed. This high false negative rate was justified because the numbers were small. Most of the other studies investigating the clinical usefulness of different reagent strips also have an appreciable false negative rate, with sensitivities ranging from $43 \%$ to $96 \%{ }^{4}{ }^{9}$

The rationale for using reagent strips to screen pregnant women attending as emergencies with symptoms of urinary tract infection is that the saving gained by reducing the number of specimens sent to the laboratory by $75 \%{ }^{2}$ outweighs the possible sequelae of untreated urinary tract infection. Such symptoms are frequently experienced in pregnant women in the absence of infection. In this scenario such a premise may well be true as a negative test result also obviates the need for antibiotic treatment. It can, however, be argued that this does not apply to patients with asymptomatic bacteriuria in early pregnancy; $25 \%$ or more of these patients will develop symptomatic urinary tract infection later in pregnancy and $15 \%$ will have persisting bacteriuria after a single course of antibiotics. ${ }^{6}$ The long term sequelae of urinary tract infection are sufficiently serious that all patients who have bacteriuria should be identified so that they can be treated and fol- 
- Asymptomatic bacteriuria is a potentially serious clinical condition

- Early antenatal urine screening should identify all cases to ensure adequate treatment

- Commercially available reagent strips for testing urine do perform to a sufficient standard

- The cost savings associated with reagent strips cannot be justified in this group of women

- All patients should have at least one urine specimen formally cultured in early pregnancy to exclude bacteriuria

lowed up. From our data it can be seen that the reagent strips are incapable of providing the diagnostic accuracy required in this group of women.

Data from other authors have been obtained from women at all stages of pregnancy, ${ }^{2-4-11}$ but the specimens have been incompletely identified by subgroups. One study evaluated samples obtained for routine bacteriological investigation and when clinically indicated without further comment. ${ }^{2}$ Another study failed to provide the length of gestation or the presence of symptoms, ${ }^{9}$ and one study failed to mention gestation at all. ${ }^{4}$ To our knowledge, ours is the only dataset obtained exclusively from women at 10 to 14 weeks' gestation with asymptomatic bacteriuria.

We do not intend to contradict the findings of other studies that show the partial value of using reagent strips to exclude the possibility of urinary infection. On the basis of our data, however, we believe that reagent strips are of insufficient sensitivity to warrant their use in detecting asymptomatic bacteriuria, and in this context the value of a formal culture of a midstream specimen of urine cannot be underestimated.

We thank Mr lain McFadyen for his critical reading of the manuscript and for helpful comments, and the midwifery staff of the antenatal clinic for their assistance in collecting and testing the urine samples.

Contributors: DGT conceived the idea for the study, reviewed the literature, and organised the collection and testing of samples. He also collected and analysed the data, and wrote the paper. DHR was involved in discussion around the conception of this study. He reviewed the data analysis and contributed to the paper by critical comments and suggestions. DHR will act as guarantor of the study.

Funding: None.

Conflict of interest: None.

1. Nunns D, Smith ARB, Hosker G. Reagent strip testing for significant bacteriuria in a urodynamic clinic. Br J Urol 1995;76:87-9.

2 Etherington IJ, James DK. Reagent strip testing of antenatal urine specimens for infection. Br J Obstet Gynaecol 1993;100:806-8.

3 Lenke RR, Van Dorsten JP. The efficacy of the nitrite test and microscopic urinalysis in predicting urine culture results. Am J Obstet Gynecol 1981;140:427-30.

4 Robertson AW, Duff P. The nitrite and leukocyte esterase tests for the evaluation of asymptomatic bacteriuria in obstetric patients. Obstet Gynecol 1988;71:878-81.

5 Kass EH. Chemotherapeutic and antibiotic drugs in the management of infections of the urinary tract. Am J Med 1955;18:764-81.

6 McFadyen IR, Eykyn SJ, Gardner NHN, Vanier TM, Bennett AE, Mayo ME, et al. Bacteriuria in pregnancy. J Obstet Gynaecol Br Commonwealth 1973;80:385-405.

7 Moller M, Thomsen AC, Borch K, Dinesen K, Zdravkovic M. Rupture of fetal membranes and premature delivery associated with group B streptococci in urine of pregnant women. Lancet 1984;2:69-70.

8 McFadyen IR. Urinary tract infection in pregnancy. In: Andreucci VE, ed. The kidney in pregnancy. Boston: Martinus Nijhoff, 1986:205-29.

9 McNeely SG, Baselski VS, Ryan GM. An evaluation of two rapid bacteriuria screening procedures. Obstet Gynecol 1987;69:550-2.

10 Marquette GP, Dillard T, Bietla S, Niebyl JR. The validity of the leukocyte esterase reagent test strip in detecting significant leukocyturia. Am J Obstet Gynecol 1988;153:888-9.

11 Van Dorsten JP, Bannister ER. Office diagnosis of asymptomatic bacteriuria in pregnant women. Am J Obstet Gynecol 1986;155:777-80.

(Accepted 3 October 1997)

\title{
Is the emergency (999) service being misused? Retrospective analysis
}

\author{
Clifford Mann, Henry Guly
}

The number of emergency admissions to hospitals in the United Kingdom has increased for reasons that are not fully understood. The increase can be traced back to the early 1980s and is not simply the result of organisational changes in the NHS. ${ }^{1}$ The ageing population is not the principal factor as demographic changes between 1981 and 1994 account for only 5.6\% of the total increase in emergency admissions, and the increase has occurred in all age groups. More important is the increase in the proportion of patients admitted several times over a five year period: this number rose by $92 \%$ between $1981-5$ and $1990-4 .{ }^{1}$

Other causes cited for the increase in emergency admissions include higher patient expectations and a rise in referrals from general practitioners. ${ }^{2}$ Both general practitioners and hospital doctors have become increasingly fearful about litigation. ${ }^{1}$ The falling death rate among patients admitted as emergencies indicates that patients are being admitted with less serious prob- lems than before, ${ }^{3}$ and most researchers are agreed that the increase is too steep to be explained by a worsening of the health of the population. ${ }^{1}$

In the United Kingdom the number of emergency (999) calls to the ambulance service has increased. In the area served by the Westcountry Ambulance Service the number of such calls increased by $28 \%$, from 74141 in 1993-4 to 94730 in 1996-7. Many 999 calls to the ambulance service have been claimed to be inappropriate. ${ }^{4}$ We determined whether the recent rise in 999 calls represented an increase in inappropriate calls.

\section{Subjects, methods, and results}

This accident and emergency department is the only such department serving a mixed urban and rural population of 410000 . Details of all new patients brought by ambulance to the department from 1993 to 1996 were taken from the department's database. Severity of illness or injury was assessed using the out-
Department of Accident and Emergency Medicine, Derriford Hospital, Plymouth PL6 8DH Clifford Mann, senior registrar Henry Guly, consultant

Correspondence to: Dr Mann iain.grant@phnt. swest.nhs.uk

BMJ 1998;316:437-8 